\title{
Organizações partidárias e seleção de candidatos no estado de São Paulo
}

\author{
Maria do Socorro Sousa Braga \\ Departamento de Ciências Sociais \\ Universidade Federal de São Carlos
}

\begin{abstract}
Resumo: O objetivo deste artigo é investigar uma das principais funções dos partidos políticos em uma democracia representativa: organizar e controlar a produção de representação. Para isso, dois processos intrapartidários serão examinados: a formação e manutenção da estrutura organizacional e a seleção de candidatos à Câmara dos Deputados realizados pelo PFL, PP, PMDB, PSDB e PT no estado de São Paulo. A proposição que orienta a análise é que quanto maior o controle dos partidos políticos sobre esses dois processos, maior será a vitalidade de suas organizações partidárias na dinâmica representativa.
\end{abstract}

Palavras-chave: seleção de candidatos; partidos políticos; comportamento político; lista partidária; eleições internas.

\begin{abstract}
This paper aims to investigate one of the main roles of political parties in a representative democracy: to organize and to control the production of representation. In order to do that, two internal party processes will be examined: the setting and maintaining of the party's organizational structure and the candidate selection for the Camara dos Deputados in the state of Sao Paulo for the PFL, PP, PMDB, PSDB and PT parties. The analysis is based on the idea that the more control political parties have over these two processes, the more vital are their party organizations in the representative dynamics.
\end{abstract}

Keywords: candidates selection; political parties; behavior politician; partisan list; internal elections. 
BRAGA, M. S. S. Organizações partidárias e seleção de candidatos...

Introdução ${ }^{1}$

O debate sobre os partidos políticos no Brasil tem se dado em torno da questão da consolidação do sistema partidário atual, traduzida na polêmica a respeito da fragilidade dos partidos e da fragmentação excessiva do sistema, bem como do impacto de tais fenômenos sobre o funcionamento do governo democrático-representativo. Para demonstrar seus argumentos, a maioria dos autores recorre ou ao desempenho eleitoral dos partidos ou ao comportamento dos atores políticos no Legislativo.

Embora a produção acadêmica já tenha acumulado conhecimento significativo sobre a formação das preferências eleitorais, de um lado, e a dinâmica das decisões legislativas, de outro, continuamos sabendo pouco sobre a participação da organização partidária na seleção dos operadores da representação no Legislativo. Passados quase vinte anos do restabelecimento do pluripartidarismo e, tendo sido realizadas doze experiências eleitorais, já dispomos de elementos razoáveis para avaliar o papel da organização partidária no controle e formação da representação política na atual experiência democrática.

Este artigo reúne elementos de análise nessa direção ao privilegiar as dinâmicas organizativas internas dos partidos com o objetivo de investigar o papel da organização na produção e controle da representação política. Esta análise pode ser lida, então, como uma tentativa de levar ao centro desse debate o partido político enquanto organização que se diferencia das demais em virtude de atuar em arenas específicas, conforme discutiremos mais adiante. Com isso, trata-se de trazer para a discussão elementos que enriquecem a polêmica sobre a debilidade partidária segundo o exame de como as organizações realmente funcionam, e não a partir de premissas normativas e institucionais.

Para o encaminhamento desta investigação, o texto foi estruturado em duas partes. A primeira apresenta os principais argumentos da literatura, constrói a crítica que me parece pertinente e desenvolve o formato geral do argumento. A segunda tem dois objetivos: primeiro, examina a estrutura organizacional que os principais partidos criaram e vêm mantendo no estado de São Paulo. Segundo, verifica como se dá o controle do processo de seleção dos candidatos a deputado federal pelos partidos PP, PFL, PMDB, PSDB e PT.

\footnotetext{
1 O material empírico deste artigo faz parte do projeto de pesquisa denominado Partidos Políticos: Organização, Recrutamento Político e Representação, desenvolvido no Departamento de Ciências Sociais da Universidade Federal de São Carlos, com financiamento da FAPESP.
} 
1 - Partidos políticos e democracia: diagnósticos e novas perspectivas de análise

Desde a redemocratização do país vem ocorrendo um amplo debate acerca das condições institucionais que dificultariam o pleno "desenvolvimento" da democracia brasileira. Os argumentos elaborados focam, primordialmente, o modelo institucional promulgado pela Constituição de 1988, cujo sistema de governo foi confirmado pelo plebiscito de 1992. Para uma parte considerável dessa literatura, o argumento principal é que a combinação de presidencialismo com representação proporcional e lista aberta produziria, necessariamente, ingovernabilidade (LAMOUNIER, 1992; MAINWARING, 1993; TAVARES, 1998; AMES, 1995). Já no que diz respeito aos partidos e sistema partidário, o diagnóstico predominante é que esse tipo de arranjo institucional incentivaria a existência de partidos fracos organizacionalmente, pragmáticos e pouco representativos.

O problema político decorrente dessa percepção é que sem o fortalecimento dos partidos, no que se refere à representação política, haveria uma conseqüente baixa institucionalização do próprio sistema de representação, o que, para uns, dificultaria ou, para outros, chegaria a impedir a consolidação da democracia. Entretanto, poucas análises abordaram os partidos políticos com base em dados empíricos consistentes relacionados à dinâmica organizacional interna. Mesmo entre esses estudos, poucos partidos foram tratados sistematicamente. Ainda menor é o número de análises que investigam a função dos partidos de selecionar pessoal político para liderar e gerir a política cotidiana.

Apesar de o processo de seleção de candidatos ser em uma das atividades centrais de qualquer organização partidária em uma democracia, seu estudo foi pouco tratado pela Ciência Política brasileira. Esta escassez parece resultar da baixa atenção dada à organização dos partidos, conseqüência direta do fato de uma parte importante da literatura tecer diagnóstico bastante crítico sobre a construção de partidos mais efetivos na atual democracia competitiva (LAMOUNIER, 1992, 1994, 1999; MAINWARING e SCULLY, 1995; MAINWARING, 1992, 1999; KINZO, 1993; MENEGUELLO, 1994; LIMA Jr, 1993). Nesse sentido, tem sido freqüentemente acentuada a fraca institucionalização dos partidos políticos, o individualismo e a autonomia dos políticos brasileiros em face da organização partidária, resultando em agremiações frágeis.

Mainwaring (1992), um dos estudiosos mais críticos dos partidos brasileiros, supõe que o controle das lideranças sobre o processo de seleção e formação da lista de candidatos é fraco quando comparado aos partidos europeus. Tal dedução baseia-se na observação das regras do sistema eleitoral e na natureza descentralizada do processo de seleção dos candidatos a cargos eletivos. No que diz respeito à variável institucional, isso ocorreria em função de dois elementos do 
BRAGA, M. S. S. Organizações partidárias e seleção de candidatos...

sistema eleitoral: a adoção da lista partidária aberta, que estimularia o individualismo nas campanhas eleitorais em detrimento de estratégias partidárias coletivistas, e o uso do dispositivo da candidatura nata, vigente até as eleições municipais de 2000.

Essa dedução é compartilhada por uma parte expressiva da literatura especializada que adota a perspectiva institucionalista para explicar os fenômenos partidários. Segundo esses teóricos, a influência do partido no processo de seleção de candidatos varia conforme o tipo de sistema eleitoral e a estrutura de autoridade partidária $^{2}$. O argumento é que, em um sistema eleitoral proporcional com lista fechada, os partidos têm pleno controle sobre esse processo pois, além de escolherem os candidatos que vão disputar as cadeiras parlamentares por sua legenda, também ordenam previamente a lista de candidatos.

Já a combinação de representação proporcional com lista aberta, ao aumentar a influência dos eleitores na seleção de candidatos, diminuiria o controle das lideranças partidárias sobre esse processo de indicação. No caso dos partidos brasileiros, seu peso seria praticamente inexistente devido ao dispositivo da candidatura nata. Com esta regra, vigente até o pleito municipal de 2000, ocupantes de cargos eletivos proporcionais nas três esferas de poder tinham automaticamente o direito de figurar na chapa partidária para o mesmo cargo político nos pleitos seguintes, independentemente da decisão do seu partido.

No que tange à estrutura de autoridade partidária, a suposição é que enquanto nos partidos centralizados as lideranças nacionais têm maior peso no processo de seleção dos candidatos, controlando o acesso à lista, nos partidos com estrutura descentralizada as decisões seriam tomadas na esfera local e as lideranças não deteriam o controle das indicações, o que implicaria maior esforço individual dos postulantes ${ }^{3}$ para compor a lista partidária. Em conseqüência, esperar-se-ia vínculos mais frouxos entre partido e deputados na Câmara, redundando em fraca coesão e disciplina parlamentar.

No Brasil, o diagnóstico predominante é que, excetuando-se os partidos de esquerda, os demais apresentam organizações nacionais muito fracas, prevalecendo o poder decisório nas instâncias estaduais. Segundo Mainwaring (2001, p.309), a irrelevância das organizações partidárias nacionais na escolha de candidatos tem como conseqüência partidos de tipo catch-all com bancadas ideologicamente heterogêneas e dirigentes nacionais com pouco poder sobre os parlamentares, redundando em baixa disciplina parlamentar.

Assim, o Brasil apresenta a combinação mais desfavorável à criação de partidos políticos nacionais fortes, com representação proporcional com lista aberta e estrutura organizacional descentralizada. A principal conseqüência disso seria a

\footnotetext{
2 Duverger, 1970; Mainwaring, 1991; Katz, 2001; Rahat e Hazan, 2001.

${ }^{3}$ Duverger, 1971; Carey e Shugart,1995.
} 
conformação de partidos inconsistentes programaticamente e com débil controle sobre as principais decisões partidárias quanto à dinâmica de representação.

Minha objeção tem início com a derivação feita do sistema eleitoral para o comportamento dos políticos com relação aos partidos pelos quais conseguiram uma candidatura. Não é evidente que, em vista dos incentivos gerados pela lógica de funcionamento da representação proporcional com listas abertas, os candidatos (e eleitos) mantenham deliberadamente vínculos frouxos com seus partidos visando constituir uma reputação pessoal em detrimento de uma ação coletiva que propicia a sobrevivência da organização. Ao contrário disso, argumento que, se, por um lado, independentemente do tipo de sistema eleitoral, haverá políticos dispostos a investir maior energia e mais recursos visando sua carreira pessoal, por outro lado, haverá políticos trabalhando para manter a organização partidária funcionando e mesmo cooperando com diversos recursos para incrementar e fortalecer a estrutura organizacional, o que lhes permitirá manter sua posição na organização e, sobretudo, Ihes ajudará a avançar em sua carreira política.

Para que o argumento funcione é preciso demonstrar a validade da premissa segundo a qual os partidos buscam sua "estabilidade organizativa", isto é, procuram manter uma linha de autoridade no seu interior. Esta linha de ação, por sua vez, é defendida pela coalizão dominante, que é conformada por dirigentes partidários e parlamentares fundadores (ou comprometidos com a continuidade da organização) do partido.

Segundo estudiosos da teoria da organização, particularmente Panebianco (2005), a chave para o sucesso da estabilidade organizativa de um partido repousa na distribuição, pela coalizão dominante, de incentivos coletivos e seletivos para os membros partidários. Para isso, aquela coalizão, isto é, a elite dirigente do partido, precisa ter o controle dos recursos vitais. Esses recursos são chamados, por Panebianco, de "zonas de incerteza", constituídas pelos seguintes aspectos: a competência (saber especializado no manejo das relações político-organizativas internas e externas ao partido); as relações com o ambiente externo; a comunicação interna; controle das regras organizativas; fontes de financiamento e o recrutamento político.

Embora Panebianco ressalte o caráter cumulativo desses recursos para que haja a estabilidade organizacional, a verificação de todos esses aspectos requer uma ampla agenda de pesquisa. Para dar conta da preocupação central deste artigo, que é o exame do papel dos partidos na seleção dos operadores da representação e do seu controle sobre a formação da lista partidária ao Legislativo federal, focalizamos unicamente o recrutamento político. A esta "zona de incerteza" acrescento uma outra que é o controle sobre o acesso à lista partidária. Isso porque minha suposição é que, apesar de o sistema de representação brasileiro ser proporcional com lista aberta, o que teoricamente possibilita ao eleitorado a sua 
BRAGA, M. S. S. Organizações partidárias e seleção de candidatos...

ordenação, os dirigentes partidários, na prática, ao manterem o controle sobre o processo de seleção dos candidatos e o acesso à lista e a recursos partidários importantes (especialmente o fundo partidário e o tempo no horário gratuito no rádio e na TV), acabam realizando uma ordenação informal dos candidatos.

Desse modo, ao contrário do que sustenta a literatura sobre os partidos brasileiros, outro argumento defendido neste artigo é que, por meio do controle do processo de seleção de candidatos e da ordenação informal da lista partidária, os partidos brasileiros vêm tendo um papel fundamental na dinâmica de formação de uma elite política responsável por operar a representação política. Esse controle, por sua vez, é feito de maneira mais centralizada e concentrada conforme o modelo de organização partidária examinado.

2 - Estrutura organizacional e dirigentes partidários: partidos centralizados ou descentralizados?

\section{1 - Introdução}

A maneira como as organizações partidárias se estruturam e funcionam revela características importantes sobre os modelos de partidos que predominam em um sistema partidário e, em última análise, sobre o próprio sistema político. Para o seu entendimento, de acordo com Panebianco (2005) e Katz e Mair (1994), práticas organizacionais, regras internas, formação da coalizão dominante e o processo de seleção dos candidatos são variáveis analíticas primordiais, pois determinam o acesso ao poder interno do partido político, assim como afetam as relações desse ator político com o Estado e a sociedade civil.

A proposição que orienta esta análise é que quanto maior o controle dos dirigentes partidários sobre o processo de seleção dos candidatos, bem como sobre as demais zonas de incerteza, maior será a vitalidade de suas organizações partidárias na dinâmica representativa. No entanto, antes de examinar o processo de seleção das candidaturas, é necessário verificar qual é a estrutura organizacional e a adesão de adeptos a cada um dos partidos estudados. 


\section{2 - A estrutura organizacional do PP, PFL, PMDB, PSDB e PT no estado de São Paulo}

A estrutura dos partidos brasileiros está organizada de acordo com o formato geral definido pela Lei Orgânica dos Partidos Políticos, que determina a criação de órgãos e instâncias de decisão aos níveis nacional, estadual e municipal, além de conselhos especializados e de departamentos de representação setorial. Para avaliar qual é a estrutura organizacional que cada partido examinado possui atualmente, a Tabela 1 apresenta o número de diretórios e comissões provisórias no estado de São Paulo. Os diretórios nacional, estaduais, municipais e zonais, e as comissões são órgãos de direção e ação partidária.

Tabela 1 - Número de Diretórios e Comissões Provisórias por partido em São Paulo, 2005

\begin{tabular}{|l|c|c|c|c|}
\cline { 2 - 5 } \multicolumn{1}{c|}{} & $\begin{array}{c}\text { Diretório } \\
\text { Estadual }\end{array}$ & $\begin{array}{c}\text { Diretórios } \\
\text { Municipais }\end{array}$ & $\begin{array}{c}\text { Comissões } \\
\text { Provisórias }\end{array}$ & $\begin{array}{c}\text { Sem } \\
\text { organização }\end{array}$ \\
\hline PDS/PP & $\begin{array}{c}\text { Comissão } \\
\text { Provisória } \\
\text { Estadual }\end{array}$ & 0 & 585 & 56 \\
\hline PFL & 1 & 207 & 438 & \\
\hline PMDB & 1 & 555 & 84 & 06 \\
\hline PSDB & 1 & 615 & 15 & 15 \\
\hline PT & 1 & 299 & 323 & 23 \\
\hline
\end{tabular}

Fonte: Elaboração própria a partir de dados do TRE-SP, do Diretório Regional do PMDB, PT e PSDB e site do PP.

Segundo os estatutos e informações relatadas por membros dos partidos em entrevistas, os diretórios são autônomos em relação à instância superior no que diz respeito às decisões relacionadas à organização, à escolha de dirigentes e à seleção de quadros a cargos eletivos, mas são subordinados às mesmas no que diz respeito aos recursos para manter a infra-estrutura básica. Na estrutura partidária, os órgãos mais frágeis são as comissões provisórias porque são totalmente dependentes dos diretórios. Normalmente, a maior incidência de comissões provisórias ocorre no início da formação e expansão da estruturação do partido. Depois disso, a freqüência de comissões provisórias geralmente resulta do controle da direção partidária sobre o processo de seleção não só de candidatos, mas também de membros do diretório local e de delegados que participarão de outros eventos deliberativos.

Ainda de acordo com as informações da Tabela 1, os cinco partidos examinados são desigualmente estruturados pelo estado de São Paulo. Tomados 
BRAGA, M. S. S. Organizações partidárias e seleção de candidatos...

os 645 municípios paulistas, o Partido Progressista (PP) apresenta a estrutura organizacional mais frágil, possuindo apenas órgãos internos provisórios, inclusive o diretório estadual. Essa ampla estrutura provisória reflete a grave crise que o partido vem passando no estado em função de conflitos intrapartidários, particularmente em razão de denúncias de corrupção envolvendo o principal dirigente e político, o ex-prefeito da capital Paulo Maluf. Mesmo assim, o partido mantém-se na maior parte das 645 cidades, ausente apenas em 56.

Ademais, conforme a Tabela 2, a seguir, o PP tem hoje cerca de 220 mil filiados no estado. Comparando-se esse número ao longo dos anos observa-se uma tendência de queda. Esse montante fica abaixo de todos os demais partidos examinados. A maneira como o PP está organizado é um exemplo evidente de um tipo de partido de quadros cujo controle interno é mantido por poucos "notáveis". A disputa interna reduz-se a dois grupos: o liderado por Paulo Maluf e o controlado pelo deputado federal Celso Russomano. Este último grupo tem mantido o poder utilizando-se de expedientes como a intervenção em diretórios, hoje comissões provisórias, e a não realização de eleições internas. As direções e executivas . órgãos deliberativos - são compostas praticamente pelos parlamentares vinculados aos respectivos grupos.

Tabela 2 - Número de filiados por partido em São Paulo, 1988, 1990, 2002, 2004, 2006

\begin{tabular}{|l|c|c|c|c|c|}
\cline { 2 - 6 } \multicolumn{1}{c|}{} & 1988 & 1990 & 2002 & 2004 & 2005 \\
\hline PDS/PP & 254.411 & 254.902 & 252.396 & 230.781 & 223.927 \\
\hline PFL & 145.404 & 146.409 & 115.619 & 129.279 & 128.628 \\
\hline PMDB & 809.931 & 776.491 & 574.210 & 515.677 & 505.927 \\
\hline PSDB & $\cdot$ & 72.290 & 216.035 & 230.605 & 226.707 \\
\hline PT & 137.892 & 153.359 & 202.401 & 241.367 & $278.873^{*}$ \\
\hline
\end{tabular}

* Esse dado foi informado pelo TRE.SP. No Diretório estadual do PT esse dado foi reduzido para 196.609 filiados (em janeiro de 2006), como resultado da Campanha de refiliação de 2001.

Fonte: Elaboração própria a partir de dados do TRE.SP, do Diretório Regional do PMDB, PT e PSDB e site do PP.

Já o Partido da Frente Liberal (PFL), atual Democratas (DEM), depois de um intenso trabalho iniciado nos anos noventa para criar uma estrutura organizacional no estado com o objetivo de disputar, com o enfraquecido PP, o eleitorado conservador, encontra-se atualmente organizado em diretórios ou comissões 
provisórias em todas as cidades ${ }^{4}$. Trata-se, porém, de uma organização em fase de consolidação, pois são 437 comissões provisórias contra 207 diretórios, o que mostra que em mais da metade das cidades essa estrutura preencheu os requisitos mínimos para disputar as eleições, mas não é ainda autônoma em relação ao diretório estadual. É importante ressaltar que no caso do PFL, diferentemente do $\mathrm{PP}$, o número alto de comissões provisórias não se deve à intervenção de instância superior e sim do movimento de seus dirigentes para ampliar a rede organizacional. Em termos de direção, a coalizão peefelista é muito centralizada, sendo controlada por duas lideranças estaduais: o ex-governador Cláudio Lembo e o atual prefeito, Gilberto Kassab. O exame das composições do diretório estadual e da executiva atesta que, embora tenha ocorrido a inserção de novos membros - geralmente parlamentares eleitos pela agremiação, os dois dirigentes mantiveram-se como presidente e vice-presidente dos diretórios estadual e da capital, respectivamente, desde a década de noventa ${ }^{5}$.

O aumento da rede organizacional do PFL também resultou em correspondente elevação do número de filiados ao partido depois de 2000. Conforme mostra a Tabela 2, depois de uma tendência de queda nos anos noventa, o PFL voltou a crescer nos anos seguintes.

Tanto no PP quanto no PFL a grande maioria de seus filiados não participa da vida partidária. Mesmo nas convenções, instâncias máximas de deliberação, as principais decisões referentes à formação das listas partidárias, coligações, candidaturas majoritárias e composição das direções e executivas estaduais são tomadas por poucos dirigentes. O número de filiados apresentado na série histórica da Tabela 2 corresponde mais ao cumprimento de exigência da legislação partidária. De acordo com a norma vigente, para a criação de um diretório, o partido precisa ter um mínimo de filiados, fixado conforme o tamanho do eleitorado do município.

A estrutura organizacional do Partido do Movimento Democrático Brasileiro (PMDB) continua sendo a mais extensa do estado, com o maior número de diretórios municipais. Os peemedebistas não estão organizados em apenas seis das 645 cidades (Balbinos, Bento de Abreu, Casa Branca, Clementina, Nantes, Palmital, Sabino, Vista Alegre do Alto). No que tange às comissões provisórias, o partido se

\footnotetext{
4 Em entrevista para a pesquisa que originou este artigo, o então vice-governador Cláudio Lembo declarou que ele e o atual prefeito de São Paulo, Gilberto Kassab (2006-2008), são os articuladores políticos e responsáveis no estado pela estratégia bem sucedida de estruturação do PFL paulista. Segundo Lembo, essa estratégia visa assumir o espaço vazio deixado pelo "fracasso"do PP no estado. 5 O presidente do PFL paulista, Cláudio Lembo, teve larga experiência na vida orgânica da ARENA, quando foi presidente do diretório estadual de São Paulo. Quando da cisão no PDS, em 1985, seu grupo caminhou ao lado das lideranças criadoras do PFL nacional. Já o vice-presidente, Gilberto Kassab, começou sua carreira política pelo antigo PL de São Paulo, onde permaneceu de 1986 a 1994.
} 
BRAGA, M. S. S. Organizações partidárias e seleção de candidatos...

diferencia dos demais subdividindo essa categoria em outras três. A organização do PMDB é mais detalhadamente apresentada na Tabela 3:

Tabela 3 - Estruturas Organizacionais do PMDB, interior e capital, 2005

\begin{tabular}{|l|c|}
\hline & Interior \\
\hline Comissões provisórias aprovadas & 76 \\
\hline Comissões prov. c/ relatores & 02 \\
\hline Comissões interventoras & 06 \\
\hline & Capital \\
\hline Diretórios zonais registrados & 27 \\
\hline Comissões interventoras & 02 \\
\hline Comissões provisórias & 18 \\
\hline Sem nada & 02 \\
\hline Total & 49 \\
\hline
\end{tabular}

Fonte: Elaboração própria a partir de dados cedidos pelo Diretório Estadual do PMDB-SP.

Como os dados informam, o PMDB possui um número bem menor de comissões provisórias, seja no interior seja na capital. Esse tipo de comissão foi criado, no caso desse partido, para resgatar a organização inicial. Já as comissões interventoras representam a ação da direção estadual para conter a ascensão de outras lideranças locais que venham colocar em risco o controle da linha de autoridade do partido. Desde fins dos anos oitenta, o ex-governador Orestes Quércia e seus seguidores mantêm-se na direção do partido em São Paulo e os quadros que tentam ocupar mais espaço político nas instâncias municipais são colocados à margem do poder intrapartidário através de intervenção.

O último episódio digno de nota ocorreu nas eleições municipais de 2004, na capital paulistana. Naquele pleito, a direção estadual resolveu intervir em todos os diretórios zonais, transformando-os em comissões provisórias, convocando novas eleições internas, além de realizar nova seleção de candidatos para montar a chapa de candidatos a vereador. Um dispositivo do estatuto do PMDB, que prevê sanções para a realização de coligação sem acordo prévio com a direção estadual, garantiu legalmente a ação do núcleo dirigente. O responsável pelo impasse político foi o então presidente do diretório municipal peemedebista, vereador Jorge Leite, articulador do apoio à reeleição da ex-prefeita Marta Suplicy e da defesa da coligação com o PT para disputar as cadeiras da Câmara Municipal na eleição de 2004. Esse fato também explicita a relação hierárquica que há entre as várias esferas intrapartidárias no PMDB paulista. Como nos demais partidos, o nível local 
é autônomo, desde que siga as regras internas criadas e interpretadas pelo grupo dirigente que controla as instâncias superiores.

No que tange ao número de filiados, a Tabela 2 mostra que, embora esse número tenha diminuído de 809 para cerca de 505 mil em 2005, este montante é maior do que o de todos os demais partidos, chegando a ser três vezes maior do que o número de filiados do PFL. Em parte, essa redução se deve à cisão do grupo que veio fundar o PSDB em 1988. Com a saída de importantes quadros históricos da agremiação para criar a sigla tucana, seus adeptos seguiram o mesmo caminho. Entretanto, a participação dos filiados do PMDB-SP na vida partidária já foi bem mais intensa, particularmente até fins dos anos oitenta devido ao caráter "frentista" do partido (KINZO, 1988; MELHEM, 1998).

Em termos do número de diretórios municipais, o Partido da Social Democracia Brasileira (PSDB) é o partido com a segunda maior estrutura organizacional no estado de São Paulo. Conforme os dados da Tabela 1, os peessedebistas estão estruturados em 630 cidades. Esse crescimento da rede organizacional pode ser também percebido pelo número de filiados ao partido, que aumentou mais de três vezes o montante de 1990. Diferentemente do PP e do PFL, e próximo do PMDB, está o grau de participação dos filiados na vida partidária do PSDB. Essa maior participação é incentivada tanto para a escolha dos dirigentes partidários quanto para campanhas eleitorais. Entretanto, devido à sua origem parlamentar, as principais decisões intrapartidárias no PSDB acabam centralizadas nas mãos de poucos quadros. O último episódio ilustrativo da alta concentração do poder decisório no PSDB foi a escolha do candidato presidencial para as eleições gerais deste ano. Ante o cenário de alta disputa intrapartidária entre os grupos políticos do atual governador José Serra e do ex-governador Geraldo Alckmin, a cúpula partidária formada pelo ex-presidente Fernando Henrique Cardoso, o governador do Ceará, Tasso Jereissati, e o governador de Minas Gerais, Aécio Neves, decidiu manter essa decisão crucial para o futuro do PSDB a portas fechadas.

Um dos mecanismos organizacionais que garantem às lideranças do PSDB controlar e direcionar a ação do partido quanto à seleção de candidatos aos Legislativos e às disputas intrapartidárias entre postulantes a uma candidatura é a estrutura montada por macrorregiões ${ }^{6}$. O PSDB agrega os 630 municípios onde tem algum tipo de organização em 25 macrorregiões. De acordo com seu estatuto, as também chamadas Coordenadorias Regionais são criadas pelo diretório estadual como órgãos de cooperação tanto para coordenar a ação dos órgãos partidários na

\footnotetext{
${ }^{6}$ Segundo o secretário estadual de organização do PSDB, Evandro Luiz Losaco, em entrevista para essa pesquisa, o PSDB controla a competição intrapartidária entre os quadros a cargos proporcionais para evitar o que ele chamou de "canibalização", ou seja, a disputa na mesma região entre dois ou mais candidatos competitivos do PSDB.
} 
BRAGA, M. S. S. Organizações partidárias e seleção de candidatos...

área da microrregião como para receber e coordenar o encaminhamento à Comissão Executiva Estadual de reivindicações, sugestões e propostas dos órgãos partidários da microrregião, inclusive indicação de candidatos para composição de chapas do PSDB às eleições de âmbito estadual e federal. Essas regiões são organizadas por diversos militantes com ocupação seja nos órgãos internos do partido seja nas Casas Legislativas, como mostra o Quadro 1. Podemos ver que, dentre os membros das macrorregiões, estão 12 parlamentares com atuação nessas estruturas partidárias, o que é indicador da participação dos deputados em atividade crucial para a sobrevivência eleitoral do PSDB.

Quadro 1 - Número de filiados integrantes das macrorregiões por tipo de cargo

\begin{tabular}{|c|c|c|c|c|c|}
\hline $\begin{array}{c}\text { Membros } \\
\text { dos } \\
\begin{array}{c}\text { Diretórios } \\
\text { Municipais }\end{array}\end{array}$ & $\begin{array}{c}\text { Membro } \\
\text { do } \\
\text { Diretório } \\
\text { Estadual }\end{array}$ & $\begin{array}{c}\text { Membros } \\
\text { da } \\
\text { Executiva } \\
\text { Estadual }\end{array}$ & $\begin{array}{c}\text { Deputados } \\
\text { Estaduais }\end{array}$ & $\begin{array}{c}\text { Deputados } \\
\text { Federais }\end{array}$ & Total \\
\hline 25 & 53 & 23 & 9 & 3 & 113 \\
\hline
\end{tabular}

Fonte: Elaboração própria a partir de dados cedidos pelo Diretório Estadual do PSDB-SP.

E o que dizer da organização partidária do Partido dos Trabalhadores? Sua estrutura organizacional é uma das mais abrangentes do subsistema paulista, seja em número de órgãos locais seja em relação à rede formada nas macrorregiões. São 622 cidades com diretórios ou comissões provisórias, reorganizadas em 19 macrorregiões. Cada uma delas é formada por um coordenador e um secretário, que têm como função organizar e dinamizar a vida partidária na respectiva região, antecipando assim o processo eleitoral interno e a competição nas eleições por cargos eletivos $^{7}$. No que diz respeito ao número de filiados, esse montante mais que dobrou entre 1988 e 2005, segundo informações da Tabela 2.

O PT é o partido que apresenta o maior grau de engajamento de seus filiados e, particularmente, dos militantes (segmento mais ativo) nas atividades partidárias e, conseqüentemente, na burocracia interna e nos cargos eletivos. Dentre os incentivos organizativos, estimuladores dessa maior participação, estão os incentivos coletivos de identidade (participa-se pela identificação com a organização) e ideológicos (participa-se pela identificação com a "causa" do partido). Por mais que o PT tenha se afastado dos objetivos oficiais iniciais que motivaram sua criação por distintos setores da sociedade civil, aos olhos dos seus defensores, esses incentivos coletivos ainda persistem, mesmo que em outros

\footnotetext{
7 Informações fornecidas pelo secretário de organização estadual do PT, Luiz Turco, em entrevista para a pesquisa que derivou este artigo.
} 
patamares. No caso da ideologia organizativa, a sua persistência é fundamental, quer porque ainda é a principal fonte dos incentivos coletivos para uma parte importante dos seus filiados, quer porque exerce uma função primordial em partidos de massa, que é a de ocultar a distribuição dos incentivos seletivos dos membros da organização que não foram contemplados. Dentre os incentivos seletivos, o PT distribui incentivos de poder e material à medida que amplia sua participação nas arenas governamentais.

É importante ressaltar que não é apenas o PT que deve equilibrar a exigência de satisfazer interesses individuais por meio dos incentivos seletivos e dar conta de alimentar as lealdades organizativas que dependem dos incentivos coletivos. Isso porque, segundo Panebianco, os partidos,

"sendo ao mesmo tempo burocracias com exigências de continuidade
organizativa e de estabilidade das próprias hierarquias internas e
associações voluntárias, são os que devem garantir ao mesmo tempo
uma quota mínima de participação não-obrigatória; devem,
simultaneamente, distribuir incentivos, tanto seletivos quanto
coletivos"(PANEBIANCO, 2005, p.18).

Ao longo do processo de institucionalização do PT, o pragmatismo político de parte do núcleo dirigente nacional, mais afeito às benesses e práticas tradicionais da política brasileira, levou o partido a se situar entre os maiores partidos do Congresso Nacional, chegando, em 2002, à Presidência da República. Para isso, a partir de 2001, auge da ascensão do chamado Campo Majoritário ao poder do partido, foi instituído o Processo de Eleição Interna (o denominado PED), com a aprovação do novo estatuto do partido. A finalidade do PED é eleger entre seus filiados os dirigentes internos para as esferas municipal, estadual e nacional, além dos delegados que irão participar do Encontro estadual, onde escolherão os candidatos do partido a cargos eletivos das próximas eleições nacionais.

A Tabela 4 descreve a rede organizacional montada para realizar esse processo em 2005. Ao mesmo tempo, revela o grau de participação dos membros no processo de seleção dos quadros dirigentes e dos delegados à convenção do partido. É possível verificar também a estratégia do grupo majoritário de aumentar, progressivamente, depois de 2001, o número de filiados para garantir mais espaço dentro do partido e continuar tendo maior influência nas ações e na distribuição de recursos aos membros do campo político dominante, o que resultou na manutenção da linha de autoridade e de concepção mais pragmática e menos ideológica do partido ${ }^{8}$.

80 exame desse processo de eleição interna será mais bem desenvolvido em artigo posterior devido à sua importância para o entendimento das transformações pelas quais vem passando o partido, seja em 
BRAGA, M. S. S. Organizações partidárias e seleção de candidatos...

Tabela 4 - Organização do PT para o Processo de Eleição Direta - PED

\begin{tabular}{|c|c|c|c|c|c|c|}
\hline $\begin{array}{c}\text { Data } \\
\text { (Set/Ano) }\end{array}$ & $\begin{array}{c}\text { PT } \\
\text { Organizado } \\
\left(n^{\circ} \text { cidades }\right)\end{array}$ & $\begin{array}{l}\% \\
\mathrm{SP}\end{array}$ & $\begin{array}{l}\text { Cidades aptas } \\
\text { participantes } \\
\text { do PED }\end{array}$ & $\begin{array}{l}\text { Filiados } \\
\text { (Set) }\end{array}$ & Observação & $\begin{array}{c}\mathrm{DM} / \mathrm{CP} \\
\text { com } \\
\text { computado } \\
r \text { do PT }\end{array}$ \\
\hline 2.000 & 425 & $66 \%$ & $\cdots .$. & & & $\cdots \cdot$. \\
\hline 2.001 & 509 & $79 \%$ & 383 & 227.963 & 47.003 votaram no PED & $\cdots \cdots$ \\
\hline 2.002 & 523 & $81 \%$ & $\cdots \cdots$ & 56.326 & Após recadastramento & $\cdots \cdots$ \\
\hline 2.003 & 558 & $87 \%$ & $\cdots \cdots$ & 105.078 & $\cdots \cdots$ & $\cdots \cdots$ \\
\hline 2.004 & 622 & $96 \%$ & $\cdots \cdots$ & 190.084 & $\cdots \cdots$ & 490 \\
\hline 2.005 & 622 & $96 \%$ & 563 & 192.017 & Em 18/Set/2.004 & 490 \\
\hline
\end{tabular}

Fonte: Elaboração própria a partir de dados cedidos pelo Diretório estadual de São Paulo e site do PT Nacional.

Os dados revelam ainda que o aumento dos filiados se deu paralelamente à extensão da rede organizacional petista, atingindo $96 \%$ das cidades do estado em 2005.

Uma questão relevante a ser investigada posteriormente é o papel do PED tanto na reestruturação do poder dos grupos internos quanto na dinâmica de arregimentação de sua militância e de adoção de práticas tradicionais condenáveis da política brasileira. A minha hipótese é que a criação do PED foi uma manobra do grupo majoritário na coalizão dominante para reduzir a participação da militância engajada, mais concentrada nos setores da esquerda do partido. Uma demonstração dessa tática foi a Campanha Nacional de Filiação, ocorrida em 2002, que impôs um significativo crescimento no número de filiados; ao mesmo tempo, o partido não investiu na formação política, antiga marca do PT.

Visto como os partidos analisados estão consistentemente organizados no estado de São Paulo, à exceção do PP, investigamos como cada um realiza o processo de seleção dos candidatos à Câmara dos Deputados, de forma a avaliar o grau de controle desses atores políticos sobre a seleção e formação da classe política paulista.

relação à organização, bem mais próxima dos demais partidos, seja no que diz respeito ao apelo eleitoral cada vez mais aberto aos diversos segmentos da sociedade. Outra hipótese a ser testada em futuro artigo é a de que, com a dinâmica do PED, o grupo majoritário conseguiu articular uma estratégia de barrar o crescimento dos grupos mais à esquerda e, dessa maneira, manter-se controlando a linha de autoridade dentro do PT. 


\section{3 - Partidos e recrutamento político: selecionando os candidatos a deputado federal}

Uma das principais funções dos partidos políticos no processo democrático é a seleção de candidatos a cargos eletivos. De acordo com alguns autores, a importância dessa atividade partidária decorre de dois fatores: primeiro, é a chave do processo de recrutamento político em uma democracia representativa. Segundo, é um dos momentos mais significativos no que concerne aos conflitos intrapartidários. O processo de seleção revela muito sobre a disputa interna, de que forma ela se dá, com que intensidade e como é resolvida9 . Isto é, permite examinar a dinâmica interna de uma organização partidária. Por isso mesmo, outros autores afirmam que a questão da designação dos candidatos é um elemento essencial em qualquer definição de partido político ${ }^{10}$.

Além disso, os métodos que são usados para selecionar afetam tanto os tipos de postulantes que serão eleitos quanto o comportamento destes na Câmara dos Deputados ${ }^{11}$. Mas, sobretudo, o processo de seleção é um dos momentos centrais da vida dos partidos porque permite conhecer seu funcionamento interno e, o mais importante, identificar sua estrutura de autoridade ${ }^{12}$.

Para avaliar os mecanismos de seleção de candidatos usados pelos partidos e suas conseqüências focalizamos na seção seguinte as dimensões analíticas relacionadas ao tipo de candidato, de selecionadores e do método de escolha. A análise é realizada com base tanto nas regras formais determinadas pela legislação eleitoral e partidária como naquelas estabelecidas nos estatutos dos partidos. As regras formais são ainda confrontadas com procedimentos informais observados nas convenções partidárias realizadas no primeiro semestre de 2006.

\footnotetext{
9 Schattschneider, 1941; Gallagher e Marsh, 1988; Katz, 2001.

10 Key, 1956; Sartori, 1976; Schelesinger, 1991.

${ }^{11}$ Gallagher e Marsh, 1988; Carey e Shugart, 1995.

12 Katz e Mair,1995; Ranney,1981; Schattschneider, 1941.
} 
BRAGA, M. S. S. Organizações partidárias e seleção de candidatos...

\subsection{1 - Quem pode ser candidato ${ }^{13}$ ?}

A primeira dimensão a considerar nesse processo é a relacionada com quem pode ser escolhido como candidato nas eleições. Interessa responder às seguintes questões: todos os cidadãos podem apresentar-se como candidatos ou somente os militantes do partido ou, ainda, entre os militantes apenas aqueles que cumprem um conjunto de critérios? No caso de haver restrições, estas são de natureza interna ao partido ou de caráter externo, ou seja, estabelecidas por lei?

Para analisar essa dimensão, temos que examinar tanto o que dispõe a legislação eleitoral sobre quem pode ser candidato quanto o que prescreve o partido. Nos contextos em que os partidos estão condicionados pelas regras do sistema político, essas duas formas estão relacionadas entre si, incidindo sobre a natureza dos candidatos escolhidos.

Os critérios que um postulante deve cumprir para obter uma candidatura podem ser classificados em um contínuo que vai desde um nível maior de inclusão até outro que supõe uma maior exclusão no processo de seleção de cada partido. De acordo com essa dimensão (ver Tabela 5), a variável pode apresentar distintos valores: a inclusão de todos os cidadãos, apenas os seus membros/filiados ou, dentre estes, somente os que cumprem uma série de requisitos. No caso dos partidos em que todos os cidadãos podem participar como candidatos, supõe-se que o processo é mais amplo e inclusivo do que os outros. No extremo oposto do contínuo estão os processos nos quais somente podem se apresentar os membros do partido que cumpriram os requisitos, tais como os que têm determinado tempo de filiação, os que contribuíram financeiramente com determinado valor, os que exerceram cargos em algum órgão partidário, os que possuem determinado grau de escolaridade, entre outros.

Tabela 5 - Quem pode ser candidato e grau de inclusão

\begin{tabular}{|c|c|c|}
\hline \multicolumn{3}{|c|}{ Maior inclusão } \\
\hline Todos os cidadãos & $\begin{array}{c}\text { Todos os membros do inclusão } \\
\text { partido }\end{array}$ & $\begin{array}{c}\text { Membros partidários que } \\
\text { cumpriram requisitos }\end{array}$ \\
\hline
\end{tabular}

Fonte: Freidenberg e López, 2001.

\footnotetext{
13 Essas dimensões analíticas foram elaboradas a partir dos trabalhos de Rahat e Hazan, 2001; Billie, 2001; Gallagher e Marsh, 1988 e Freidenberg e Lópes, 2001. Todos esses estudos apresentam uma série de perguntas sobre esse tema realizadas em outros contextos que, na medida do possível, foram incorporadas nesta construção analítica para examinar o caso brasileiro.
} 


\subsection{2 - Condições para ser candidato a deputado federal no Brasil}

A observação do cenário partidário brasileiro revela que quem quer ser candidato a deputado federal deve cumprir, de um lado, os requisitos da regra eleitoral nacional ${ }^{14}$ e, de outro, os que the impõe cada partido. A lei eleitoral estipula que todos os cidadãos têm o direito de eleger e, ao mesmo tempo, de serem eleitos para cargos de representação popular desde que preencham uma série de atributos: nacionalidade, idade (de 21 anos para deputado federal), não ter causas penais pendentes e ter filiação partidária na circunscrição por onde pretende concorrer. Esse último quesito é salientado no Art.9: "Para concorrer às eleições, o candidato deverá possuir domicílio eleitoral na respectiva circunscrição pelo prazo de, pelo menos, um ano antes do pleito e estar com a filiação deferida pelo partido no mesmo prazo" (grifos da autora).

Dessa forma, a lei eleitoral obriga que todas as candidaturas sejam registradas por meio dos partidos políticos, o que coloca o Brasil entre os poucos países na América Latina que dão o monopólio da representação política às organizações partidárias ${ }^{15}$. Em princípio, portanto, esse monopólio partidário, ao garantir o controle das lideranças sobre as oportunidades de acesso a postos para aspirantes a carreiras políticas, permite a seus dirigentes a imposição de lealdades e a manutenção das relações hierárquicas.

A legislação eleitoral (Lei 9504/97) também estipula no capítulo sobre as convenções para escolha de candidatos que "As normas para a escolha e substituição dos candidatos e para a formação de coligações serão estabelecidas no estatuto do partido, observadas as disposições desta Lel" (Art. $7^{\circ}$ ). Já que são os partidos que formulam as regras de seleção de candidatos por meio de seus estatutos, é necessária sua observação para ver se existem mais restrições além daquelas ditadas pela lei.

No que diz respeito ao PFL, o estatuto dispõe que:

"Art.80 - Para participar das Convenções e demais atos partidários, com direito a votar e ser votado, o eleitor deverá estar filiado ao PFL até cinco dias antes do evento, excluído o dia da sua realização."

\footnotetext{
14 Para a análise das regras eleitorais foram consultados o Código Eleitoral, Coleção Saraiva de Legislação. São Paulo: Saraiva, 2002, e a Constituição Federal de 1988.

$15 \mathrm{Na}$ América Latina, apenas a legislação eleitoral de El Salvador e Equador, até 1996, apresentaram essa exigência (FREIDENBERG e LÓPEZ, 2001, p.167).
} 
No entanto, para participar do processo de seleção dos candidatos a cargos públicos, vale a legislação eleitoral: o "Art.9 - Para concorrer a cargo eletivo o eleitor deverá estar filiado ao PFL no prazo estabelecido na legislação eleitoral vigente".

Já no PSDB, o estatuto informa que:

"Art. 14 - São direitos dos filiados:

(...)

III - votar e ser votado para os órgãos do Partido;

$\$ 1^{\circ}$. Somente poderá votar e ser votado o filiado que contar, no mínimo, 6 (seis) meses de filiação, excetuados os casos de constituição do primeiro Diretório Municipal ou Zonal, ou nos de dissolução ou extinção de Diretório, quando poderá participar da convenção, convocada pela Comissão Provisória, com todos os direitos que the são atribuídos, o filiado que contar, no mínimo, com 30 dias de filiação".

(...)

$\$ 3^{\circ}$. Nenhum cidadão poderá ser escolhido como candidato do Partido a qualquer cargo eletivo se não estiver filiado, pelo menos, um ano antes da data fixada para a realização das eleições, majoritárias ou proporcionais".

Como o PFL, o PSDB segue a legislação exigindo que os candidatos do partido sejam escolhidos entre seus membros que estejam filiados há pelo menos um ano.

O estatuto do PMDB não é diferente dos estatutos do PSDB e do PFL:

"Art. 8". São direitos dos filiados:

(...)

$\$ 2^{\circ}$. Somente poderá ser candidato a cargo eletivo o filiado que, na data da eleição, contar com no mínimo um ano de filiação partidária."

No PP, a situação não é diferente:

"Art. 74. Aos filiados ao Partido são assegurados os seguintes direitos partidários:

I - disputar, observadas as exigências da Constituição, da lei e deste Estatuto, cargo público eletivo e função partidária." 
Em contrapartida, no PT, as restrições vão além do que exige a legislação:

“Art. 128: São pré-requisitos para ser candidato do Partido: estar filiado ao Partido, pelo menos, um ano antes do pleito;

a) estar em dia com a tesouraria do Partido;

b) assinar e registrar em Cartório o "Compromisso Partidário do Candidato Petista", de acordo com modelo aprovado pela instância nacional do Partido, até a realização da Convenção Oficial do Partido.

S 1 : A assinatura do "Compromisso Partidário do Candidato Petista" indicará que o candidato está previamente de acordo com as normas e resoluçóes do Partido, tanto em relação à campanha quanto ao exercício do mandato.

\& 2: Quando houver comprovado descumprimento de qualquer uma das cláusulas do "Compromisso Partidário do Candidato Petista", assegurado o pleno direito de defesa à parte acusada, o candidato será passível de punição, que poderá ir da simples advertência até o desligamento do Partido com renúncia obrigatória ao mandato"

É importante salientar que o "Compromisso Partidário do Candidato Petista" é um documento criado pelo Diretório Nacional do PT, por meio do qual o partido estabelece normas, com abrangência nacional, para o comportamento do candidato durante a campanha e depois de eleito. Este documento é um bom exemplo dos meios elaborados pelos dirigentes petistas para fortalecerem o seu controle sobre as candidaturas e respectivas campanhas eleitorais e, também, sobre os quadros eleitos. Dentre outras regras, cabe chamar atenção para as seguintes condições: obriga todo candidato a contribuir financeiramente com o partido e a veicular a sigla do partido em seu material de campanha e ainda restringe o financiamento de campanha. Caso eleito, o documento reforça o caráter partidário do mandato, seja por meio do dever de submeter ao partido os nomes que irão compor o primeiro e segundo escalão do governo, seja por meio de formar uma "bancada coletiva", no caso do Legislativo.

Como se vê, dentre os partidos analisados, o processo de seleção de candidatos do PT é o de maior exclusão, exigindo, além da filiação por um ano, contribuição financeira, compromisso programático e aprovação pela direção partidária ou apoio de parcela dos membros. Uma das explicações para esse padrão está na sua origem extra-parlamentar, mais vinculado a variados setores sociais, bem como ao seu perfil ideológico e à sua estratégia organizacional. 
BRAGA, M. S. S. Organizações partidárias e seleção de candidatos...

De acordo com estes dados, é possível classificar os principais partidos brasileiros em um ponto intermediário do intervalo "maior inclusão - maior exclusão", tendendo mais para este segundo pólo devido às exigências encontradas no PT. Isso é o que mostra a Tabela 6.

Tabela 6 - Requisitos para ser candidato segundo a Lei Eleitoral e os Estatutos Partidários

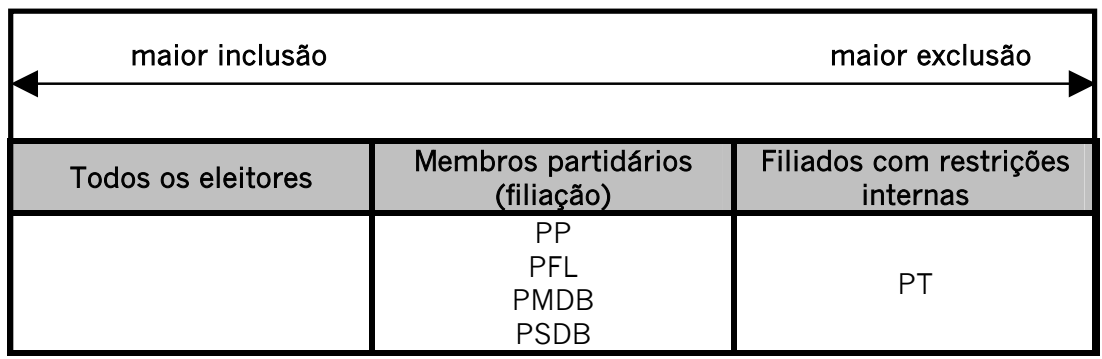

Fonte: elaboração própria a partir do Código Eleitoral e Estatutos Partidários.

\subsection{3 - Quem escolhe os candidatos?}

A segunda dimensão a ser observada no processo de seleção partidária está vinculada ao quadro de membros responsáveis pela escolha dos candidatos (os selecionadores). A identificação do corpo que detém esse controle revela os vários processos de tomada de decisões intrapartidários e indica os tipos de relações existentes entre os membros e aderentes do partido. Assim, por exemplo, a seleção realizada por meio de eleições internas sinaliza um nível maior de inclusão dos membros nesse processo decisório, ao passo que a escolha realizada por um único dirigente mostra uma estrutura decisória fechada e mais rígida.

O exame dessa relação é fundamental, pois viabiliza um raciocínio teórico sobre os vínculos existentes entre os dirigentes partidários tanto com seus filiados quanto com os futuros representantes. Vários estudos têm avaliado esse aspecto por meio de um contínuo que representa os vários graus de inclusão da seleção. Dessa maneira, nos extremos, temos o caso dos candidatos escolhidos pelo líder do partido, que detém o monopólio da seleção e, do outro lado, a possibilidade de que a seleção seja realizada por meio das primárias, definindo, portanto, um nível máximo de participação. Estes são, evidentemente, os casos extremos que encontram pouca evidência no mundo real. Mesmo o caso dos partidos americanos, que adotam as primárias, não constitui um claro exemplo de sistema seletivo altamente aberto. De fato, o processo de nomeação ocorre por meio das primárias, 
mas varia muito entre os estados, já que, em muitos casos, é a liderança partidária local que define a candidatura (EPSTEIN, 1980).

No que diz respeito às relações com os parlamentares, no caso em que a candidatura é definida por um único líder, supõe-se que haja maior disciplina interna, já que o aspirante depende mais dos dirigentes para conseguir uma candidatura. O contrário pode ser observado nos ambientes em que a nomeação depende mais dos votantes, embora o aparato partidário mantenha-se controlando a estrutura de oportunidades.

Neste artigo, os métodos usados para selecionar os candidatos são classificados conforme o grau de inclusão ${ }^{16}$. Em um extremo do contínuo situa-se o mecanismo com o mais alto nível de inclusão, enquanto no outro extremo é somente um líder que seleciona. Entre esses dois extremos podemos identificar diversos mecanismos com variados níveis de participação. Assim, de acordo com o nível de inclusão verificado, temos um determinado tipo de controle do processo de escolha (Tabela 7).

Para termos maior clareza sobre quem e como são designados os candidatos, examinamos também os procedimentos usados nessa seleção. Esses métodos podem ser por votação envolvendo todos os filiados, somente os militantes, ou envolvendo ambos, ou por indicação (nomeação). Segundo Rahat e Hazan (2001), estamos diante de um procedimento de votação quando o processo de seleção utiliza o voto para decidir quem será o candidato e qual sua posição na lista. Para isso, esse sistema requer que o candidato seja escolhido apenas pelo voto, o que significa que não pode haver um acordo sobre uma lista. Ademais, os resultados devem ser legitimados por divulgação oficial. Ainda de acordo com esses autores, uma candidatura é definida por um sistema de nomeação quando são as lideranças do partido que indicam os candidatos que comporão a lista partidária.

Tabela 7 - Quem e como escolhe os candidatos, segundo o grau de inclusão

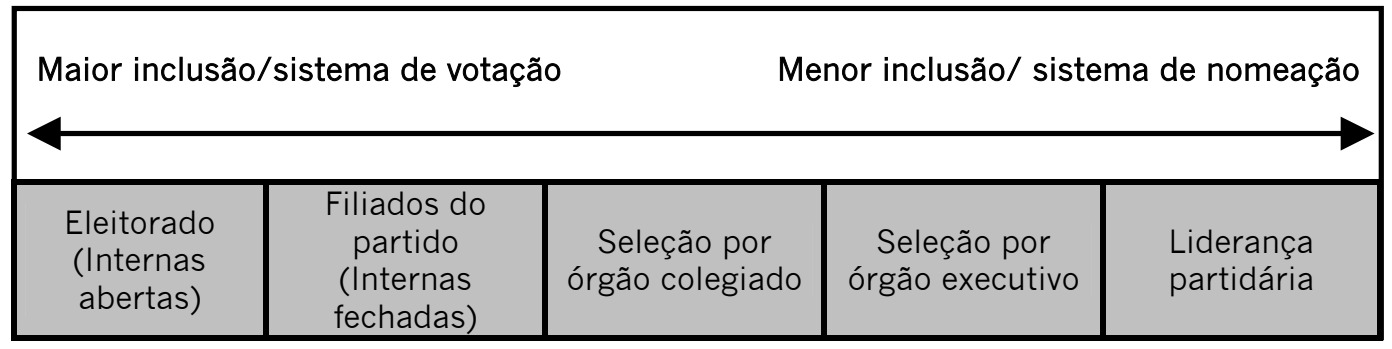

Fonte: Freindenberg e López, 2002.

\footnotetext{
${ }^{16}$ Essa classificação segue orientação dos trabalhos de Rahat e Hazan (2001).
} 
BRAGA, M. S. S. Organizações partidárias e seleção de candidatos...

\subsection{4 - Quem (e como) escolhe os candidatos a deputado federal nos principais partidos do estado de São Paulo?}

O exame da dimensão quem realiza a escolha dos candidatos proporcionais e por quais sistemas de designação deve ser feito considerando, particularmente, variáveis endógenas aos partidos. Isso porque a legislação eleitoral confere autonomia às organizações partidárias para definir suas regras internas no que tange a essa questão. Ademais, a lei estabelece mecanismos específicos para a escolha e/ou homologação das candidaturas, que são as convenções, assim como dita os prazos máximos para sua realização e registro dos candidatos nos órgãos oficiais da justiça eleitoral ${ }^{17}$.

Os estatutos do PFL, PP, PMDB e PSDB não diferem muito sobre quem escolhe os candidatos do partido. É a convenção partidária estadual que homologa as chapas neles apresentadas. A observação da dinâmica das suas convenções para as eleições de 2006 revelou que há diferenças importantes entre eles no que diz respeito à participação dos filiados nesse processo de seleção. Com relação ao PP e ao PFL, a convenção funciona apenas como ato simbólico, onde a lista partidária é homologada pelos presentes sem que haja menção dos componentes e mesmo sem qualquer discussão sobre possíveis nomes a serem incluídos na lista previamente elaborada por seus dirigentes. Trata-se, portanto, de um sistema de nomeação puro, ou seja, os candidatos integrantes das listas do PP e do PFL não passam por um processo de aprovação, configurando processos mais exclusivos.

Outro indicador que reforça o caráter restritivo do processo nesses dois partidos é que não houve, anteriormente à convenção, eleições internas para a escolha dos convencionais ou mesmo para os cargos internos. As atuais direções permanecem nas atuais posições desde a formação do partido, com um ou outro quadro sendo remanejado, outro incluído ou mesmo substituído.

Já no que diz respeito ao PMDB e ao PSDB, a participação dos filiados nas convenções e, portanto, na homologação da chapa partidária se dá de maneira mais ampla. Nesses dois partidos, embora a lista partidária também já chegue fechada na convenção, ou seja, não haja nenhuma discussão com a massa dos convencionais na sua montagem, esses participam do processo de homologação aprovando ou não a lista de candidatos previamente escolhida pela cúpula do partido. Em função disso, estamos também diante de um sistema de indicação, embora relativamente mais inclusivo, uma vez que é acompanhado por um processo de aprovação dos delegados. Esse processo de consulta ao convencional parece, em última análise, que acaba restringindo em algum grau a margem de

\footnotetext{
17 Sobre as convenções partidárias, ver o artigo 7 e prazo para a realização das mesmas no artigo 8 da
} Lei Eleitoral de n 9.504, de 30/9/1997. 
manobra dos líderes organizativos, o que implica esforços contínuos de sua parte para manter e ampliar o número de adeptos sob sua influência. Normalmente, outras questões relacionadas às estratégias eleitorais são colocadas na cédula de votação para o convencional se posicionar. Pode, por exemplo, haver consulta sobre a realização ou não de coligações com determinados partidos para os cargos majoritários e proporcionais.

Com relação aos dispositivos formais, a grande diferença aparece no documento do PT. Embora o resultado final do processo de seleção dos candidatos petistas somente seja conhecido na convenção estadual (no chamado Encontro), seu estatuto prevê o início dessa atividade de escolha no momento das indicações realizadas por diversas instâncias do partido. Isso fica explícito no artigo 129:

"Art. 129: A Comissão Executiva da instância de direção correspondente somente examinará pedido de indicação à pré-candidatura se vier acompanhado de assinaturas ou votos favoráveis de no mínimo:

$B$ - ao cargo de deputado federal:

B. a. - 1/3 dos membros do Diretório Estadual; ou

B. b. - $5 \%$ das Comissões Executivas Municipais; ou

B. c. - $1 \%$ dos filiados no Estado; ou

B. d. - Encontro Setorial Estadual ou Nacional."

O PT, por meio de seu estatuto, garante, por um lado, que amplos setores do partido participem desse processo indicando seus quadros e, por outro, procura garantir que seus candidatos possuam alguma representatividade junto ao conjunto dos filiados, valorizando de alguma forma a democracia interna. Embora haja formalmente essa preocupação, ao longo das outras etapas, um grupo mais restrito de lideranças mantém maior controle do processo. Conforme observação desse processo in loco, após a fase das indicações, os nomes são apresentados e registrados no Diretório Estadual e após seu registro, a Secretaria de Organização do partido (SORG) inicia um processo de consulta pessoal às pré-candidaturas indicadas pelo maior número de diretórios municipais. Feita esta consulta, os nomes favoráveis à sua indicação são acatados pelos dirigentes do partido.

Mas, além disso, no caso de uma determinada candidatura não se mostrar viável ou eventualmente representar um setor da sociedade civil ou uma região do estado que possua outras lideranças mais influentes, inicia-se um período de "negociações" em torno de alguns nomes. Ademais, vale ressaltar que, caso a procura por legenda exceda o limite legal ou idealizado pelo partido, fica a cargo da Comissão Eleitoral efetuar os devidos cortes e propor uma chapa que será ratificada ou alterada mediante apreciação do Encontro Estadual. A formação dessa comissão 
BRAGA, M. S. S. Organizações partidárias e seleção de candidatos...

eleitoral segue a proporcionalidade dos membros do Diretório Estadual, ou seja, os grupos internos que estão representados na executiva estadual (23 membros) indicam os nomes para a composição dessa comissão, podendo coincidir ou não com os nomes que compõem a executiva estadual. A chapa proposta pela comissão eleitoral será votada pelos delegados no encontro estadual através de uma lista contendo os nomes que a comissão sugeriu e os nomes que estariam pleiteando a legenda para concorrer às eleições. Neste último caso, haverá a abertura do plenário para defesa das novas candidaturas e votação de cada caso.

Assim, mesmo no caso do PT, onde há um processo de seleção mais inclusivo, na convenção predomina um sistema de nomeação apenas aparentemente mais ampliado, pois o voto do delegado é para uma lista de candidatos, embora possa haver a inclusão de novos nomes durante o sistema de aprovação. No entanto, dificilmente isso ocorre em função da lista petista também ser nomeada, o que garante que a sua composição seja controlada para dar conta tanto dos grupos de poder internos, quanto de certa imagem do partido junto ao eleitorado.

Uma outra questão que deve ser examinada diz respeito a quem pode participar das convenções e como ocorre sua escolha. No que tange ao processo de escolha dos convencionais, observam-se diferenças entre as instâncias partidárias. $\mathrm{Na}$ esfera local, os participantes são escolhidos por todos os filiados e nos outros casos os membros são selecionados por delegados das instâncias inferiores. Para isso, o membro precisa ter de seis meses, no caso do PP, PMDB e PSDB, a um ano de filiação, no caso do PT.

Entre os componentes das convenções do PP, PFL, PMDB e PSDB estão os membros dos diretórios em cada nível e os Vereadores, Deputados Estaduais e Federais, Senadores, Presidentes e líderes da Câmara e do Senado, o Presidente da República, Governadores e Prefeitos. É interessante observar a importância dos detentores de cargos eletivos sobre a escolha dos próximos candidatos nesses partidos. Nesse sentido, no PP, PFL, PMDB e PSDB, os deputados podem participar em mais de uma instância, isto é, são membros efetivos das convenções nas esferas nacional, estadual ou municipal. No PP, pode haver voto cumulativo, isto é, um membro pode votar na convenção estadual enquanto delegado municipal, enquanto Deputado Federal e enquanto líder da Câmara (tendo direito, portanto, a três votos).

Já no caso do PT, os selecionadores dos candidatos são desde os filiados aos diretórios municipais, com suas indicações preliminares, passando pelos membros da Comissão eleitoral estadual, até os delegados eleitos para os Encontros (convenções petistas). Neste partido, participam também dos encontros os membros dos respectivos diretórios, os membros dos diretórios estaduais e 
nacional, filiados no município e os detentores de cargos eletivos em cada nível, embora sem direito a voto.

Outro ponto que diferencia os partidos diz respeito à forma da convocação dos filiados para as convenções. A questão da convocação tem a sua relevância, pois uma vez que não seja atingido o quorum mínimo para a convenção (em torno de $20 \%$ do número de membros efetivos do diretório, num mínimo de 20 filiados, podendo variar), é possível a dissolução do diretório e a instalação de uma comissão provisória nomeada pelo diretório regional. O exame dos estatutos revela que elas ocorrem de modo mais ou menos restritivo. No PMDB, por exemplo, o artigo 26 diz o seguinte:

"Art. 26. O ato de convocação das Convenções e Diretórios deverá atender aos seguintes requisitos:

I - Publicação de edital na imprensa oficial da circunscrição eleitoral respectiva, quando existente, e afixação, com antecedência mínima de 8 (oito) dias, na sede do Partido, se houver, e nos cartórios eleitorais ou na Câmara de Vereadores.

// - Notificação pessoal, sempre que possível, no prazo de 8 (oito) dias, àqueles que tenham direito a voto;

III - designação do lugar, dia e hora do início e término da reunião, indicação da matéria incluída na pauta e objeto de deliberação."

Como se vê, no PMDB, o filiado deve ser notificado pessoalmente da data da convenção. No entanto, essa convocação acontece "sempre que possível", revelando que a relação entre o filiado e os dirigentes se dá por meios muito vagos. Poranto, a quantidade dos filiados deste partido que participa da convenção depende de seu interesse em procurar, nos devidos locais de divulgação, o edital de convocação para participar desse processo.

O PFL, PP e PSDB apresentam um processo muito próximo ao observado no PMDB; a única diferença diz respeito ao prazo em que a convocação deve ser feita.

No caso do PT, em contrapartida, a convocação é bem mais direta e ocorre, como já vimos em seção anterior, no PED - Processo das Eleições Diretas, criado em 2001 pelo auto-denominado "Campo Majoritário". Isso fica evidente no artigo 36 do estatuto petista:

"Art. 36: As urnas deverão ser instaladas em locais conhecidos, previamente designados e de fácil acesso, em quantidade suficiente para garantir a proximidade do domicílio do filiado e o exercício do voto. 
BRAGA, M. S. S. Organizações partidárias e seleção de candidatos...

\& 1: Não será permitida a existência de urnas volantes.

$\S 2^{\circ}$ : Os locais de votação devem ser indicados e amplamente divulgados pela comissão eleitoral a que se refere o artigo anterior até 30 dias antes do pleito.

\& 3: O filiado deverá votar no local designado por seu respectivo Diretório Zonal ou Municipal.

Art. 37: Antes da realização das eleições diretas, obrigatoriamente, deverão ser realizadas plenárias ou debates para a discussão da pauta, com ampla divulgação a todos os filiados, observadas as seguintes normas:

a) Na eleição da direção nacional será obrigatória a realização de debates entre os concorrentes em todas as Capitais do país;

b) na eleição das direções estaduais será obrigatória a realização de debates em todas as cidades-pólo;

c) na eleição das direções municipais será obrigatória a realização de debates em todos os zonais, quando se tratar de Diretórios com zonais, e nos principais bairros, quando se tratar de Diretórios sem zonais".

No PT, há a preocupação de que o processo de escolha ocorra perto da residência do filiado e que seja acompanhado de debates e plenárias, o que contribui para uma vida partidária mais intensa. Isso implica também que haja maior participação dos seus membros nos principais momentos decisórios do partido.

A partir de todas essas questões discutidas nesta segunda dimensão, é possível classificar o PMDB e o PSDB na zona "Seleção por órgão Executivo do partido"; já o PP e o PFL situam-se na zona "Seleção por líder partidário" e o PT, como há o envolvimento de diversos membros do partido com graus variados de influência nesse processo, está situado na zona "seleção por órgão colegiado". No entanto, no que se refere ao processo de escolha dos convencionais (selecionadores, em última instância, no PMDB, PSDB e PT), estes são designados por outros delegados, o que torna essa atividade mais exclusiva e, mais uma vez, os grupos dirigentes com maior delegação têm grande poder no resultado final. Já no PP e no PFL, os líderes partidários, incluindo parlamentares mais orgânicos, detêm total controle sobre a seleção dos candidatos e, portanto, também sobre o acesso à lista partidária, caracterizando-se, então, como os partidos mais fechados à participação popular. Apesar dessas diferenças quanto à dimensão dos selecionadores, com relação ao sistema de designação, todos os partidos examinados utilizam o mecanismo de indicação, embora tenham sido identificados 
graus variados de aprovação e, conseqüentemente, de participação dos militantes (convencionais) em cada partido. Isso é o que mostra a Tabela 8:

Tabela 8 - Quem e como escolhe os candidatos à Câmara dos Deputados e o grau de inclusão

\begin{tabular}{|c|c|c|c|c|}
\hline \multicolumn{3}{|c|}{ Maior Inclusão/sistema de votação } & \multicolumn{2}{|c|}{ Menor inclusão/sistema de nomeação } \\
\hline $\begin{array}{c}\text { Eleitorado } \\
\text { (internas } \\
\text { abertas) }\end{array}$ & $\begin{array}{c}\text { Filiados } \\
\text { (internas } \\
\text { fechadas) }\end{array}$ & $\begin{array}{l}\text { Seleção por } \\
\text { órgão } \\
\text { Colegiado do } \\
\text { partido }\end{array}$ & $\begin{array}{l}\text { Seleção por } \\
\text { órgão } \\
\text { Executivo do } \\
\text { partido }\end{array}$ & Líder partidário \\
\hline & & PT & $\begin{array}{l}\text { PMDB } \\
\text { PSDB }\end{array}$ & $\begin{array}{l}\text { PP } \\
\text { PFL }\end{array}$ \\
\hline
\end{tabular}

Vimos que os partidos examinados controlam o processo de seleção por diversos meios. Dentre os mecanismos identificados estão o método de formação da lista, isto é, por indicação e não por votação. Além desse sistema, vimos que a forma de convocação para as convenções, a possibilidade de intervenção dos diretórios de instância superior sobre as inferiores e a criação de comissões provisórias e interventoras (no caso do PMDB) são outros mecanismos utilizados pelos dirigentes partidários para garantir seu controle sobre os resultados deste processo de seleção. Observa-se que, diferentemente do que defende Mainwaring (1999), os alegados incentivos (o sistema eleitoral e a lista aberta) não têm promovido as conseqüências deletérias à imagem dos partidos. Ao contrário, os partidos mantêm alto controle sobre o processo de seleção de candidatos e ao acesso à lista partidária, embora com graus distintos de estrutuação. Dessa maneira, seus dirigentes partidários vêm agindo estrategicamente para diminuir a incerteza eleitoral e garantir a sobrevivência do partido no sistema político. Além da preocupação com o ambiente externo, em partidos em que a disputa interna é muito acirrada (como, por exemplo, o PSDB e o PT), a centralização do processo de seleção é resultado da ação das lideranças no sentido de preservar a linha de autoridade intrapartidária, o que implicará no controle de outros recursos vitais para a estabilidade organizativa e, conseqüentemente, para aumentar as chances de eleger seus candidatos nos distintos níveis de competição. 
BRAGA, M. S. S. Organizações partidárias e seleção de candidatos...

\section{Considerações Finais}

O objetivo central deste artigo foi examinar o modo como os principais partidos no estado de São Paulo escolhem seus candidatos à Câmara dos Deputados e investigar o grau de controle que as lideranças partidárias têm sobre esse processo. Foram identificados os tipos de mecanismos que são utilizados analisando-se três dimensões analíticas: quem pode ser candidato, quem e como seleciona os candidatos partidários. Nesta última dimensão, acrescentamos o tipo de sistema de seleção, se por votação ou indicação.

A análise das dimensões e da sua combinação mostrou que o processo de seleção de candidatos tende para o pólo da exclusão. A afirmação pioneira de um dos brasilianistas mais críticos dos partidos brasileiros, o estudioso Mainwaring (1991 e 2002), de que o processo de seleção de candidatos no Brasil envolveria grande participação popular e pouco controle por parte das lideranças partidárias, não têm, portanto, lastro empírico.

A investigação dos estatutos e dos resultados de convenções mostra que a participação no nível local não é tão intensa e que as lideranças possuem diversos mecanismos para restringir essa participação, desde a convocação para as convenções, limitada a poucos membros, até a intervenção em diretórios e a nomeação de comissões provisórias. E, sobretudo, os dirigentes têm assento cativo nas instâncias partidárias responsáveis pela seleção. Mesmo o PT, partido onde, formalmente, há maior abertura para o envolvimento dos filiados nesse processo, é a organização que impõe o maior número de requisitos para ser candidato. Neste aspecto é, pois, o processo mais restritivo. Vimos também que há um núcleo de lideranças na etapa final dessa atividade partidária que acaba controlando as nomeações para deputado federal. Esses mecanismos mostram que os principais partidos têm papel crucial na dinâmica de representação na jovem democracia brasileira.

Em futuros trabalhos, continuaremos analisando os processos de decisão dos partidos juntamente com o exame de outras dimensões analíticas e outras relações, particularmente as que se referem ao comportamento dos políticos e respectivos partidos no Legislativo. Finalmente, é importante ressaltar, dadas as constatações do presente estudo, que o exame da dinâmica interna dos partidos é uma condição crucial para que a pesquisa sobre o funcionamento da nossa democracia representativa possa avançar. 
Referências Biliográficas

AMES, B. "Electoral Strategy under Open-List Proportional Representation". American Journal of Political Science, vol.39, n², p.406-33, 1995.

BILLIE, L. "Democratizing a Democratic Procedure: Myth or Reality?" Party Politics, vol.7, $n^{\circ} 3,2001$.

BRAGA, M. S. S. O Processo Partidário-Eleitoral Brasileiro: Padrões de Competição Política 1982-2002. São Paulo: Humanitas/Fapesp, 2006.

BRAGA, M. e PRAÇA, S. Recrutamento Partidário: Seleção de Candidatos à Câmara dos Vereadores paulistana In: BRAGA, M. S. e KINZO, M. D’Alva (orgs.). Eleitores eRepresentação Partidária no Brasil. São Paulo: Humanitas/CNPQ, 2007.

CAREY, J. M. e SHUGART, M. S. "Incentives to Cultivate a Personal Vote: a Rank Ordering of Electoral Formulas". Electoral Studies, vol.14, n4, p.417-439, 1995.

CROZIER, M. e FRIEDBERG, E. L'acteur et le systéme. Paris: Éditions du Seuil, 1977.

DUVERGER, M. Os Partidos Políticos. São Paulo: Zahar, 1970. Les Constitutions de La France. Paris: Presses Universitaires, 1971.

EPSTEIN, L. Political Parties in Western Democracies. New Brunswick, N. J.: Transaction, 1980

FREIDENBERG, F. e LOPES, F. S. "Como se escolhe um candidato a Presidente? Regras e Práticas nos partidos políticos da América Latina". Opinião Púbica, Campinas, vol.8, n², p.158-88, 2001.

GALLAGHER, M. and MARSH, M. (eds). Candidate Selection in Comparative Perspective: The Secret Garden of Politics. London: Sage, 1988.

GUARNIERI, F. Partidos, Seleção de Candidatos e Comportamento Político. Dissertação de Mestrado. DCP.USP, 2004. 
BRAGA, M. S. S. Organizações partidárias e seleção de candidatos...

HOPKIN, J. "The Emergence and Convergence of the Cartel Party: Parties, State and Economy in Southern Europe". Paper prepared for panel on 'The New Political Economy of European Political Parties' at the Conference of Europeanists, Chicago, 2002.

KATZ, R. S. "The Problem of Candidate Selection and Models of Party Democracy". Political Studies, vol.7, n³, p.277-296, 2001.

A Theory of Parties and Electoral System. Baltimore: Johns Hopkins

University Press, 1980.

KATZ, R. e MAIR, P. (eds). How Parties Organize: Change and Adaptation in Party Organizations in Western Democracies. London: Sage Publications, 1994.

"Changing Models of Party Organization and Party Democracy: The

Emergence of the Cartel Party", Party Politics, vol.1, 1995.

KEY, V. O. American state politics: an introduction. New York: Knopf, 1956.

KINZO, M. D'Alva. Oposição e Autoritarismo: Gênese e Trajetória do MDB (1966-1979). São Paulo: Vértice, Editora dos Tribunais, 1988.

Adenauer, 1993.

Radiografia do Quadro Partidário Brasileiro. São Paulo: Fundação Konrad-

LAMOUNIER, B. Prefácio. In: LAVAREDA, A. A Democracia nas urnas. Rio de Janeiro: Revan, 1999.

A democracia brasileira de 1985 à década de 90: a síndrome da paralisia decisória. In: VELLOSO, J. P. dos Reis (Org.). Governabilidade, Sistema Político e Violência Urbana. Rio de Janeiro: José Olympio, 1994.

Estrutura Institucional e Governabilidade na década de 1990. In: VELLOSO, J. P. dos Reis (Org.). O Brasil e as reformas políticas. Rio de Janeiro: José Olympio, 1992.

LIMA, Jr. O. B. Democracia e Instituições Políticas no Brasil dos Anos 80. São Paulo: Edições Loyola, 1993. 
LIMONGI, F. Institucionalização Política. In: MICELI, S. (Org.). O que ler na ciência social brasileira (1970-1995). São Paulo: Editora Sumaré, 1999.

MAINWARING, S., O'DONNEL, G. e VENEZUELA, S. J. (eds.) Issues in Democratic Consolidation: The New South American Democracies in Comparative Perspective. Notre Dame: University of Notre Dame Press, 1992.

MAINWARING, S. e SCULLY, T. R. (eds.). Building Democratic Institutions: Party Systems in Latin America. Stanford: Stanford University Press, 1995.

MAINWARING, S. "Políticos, Partidos e Sistemas Eleitorais - O Brasil numa Perspectiva Comparada". Novos Estudos, CEBRAP, n²9, 1991.

"A democracia presidencialista multipartidária: o caso Brasil". Lua Nova, n²8-29, p. 21-74, 1993.

Rethinking Party Systems in the Third Wave of Democratization: The Case of Brazil. Stanford: Stanford University Press, 1999.

Mercado Aberto, 2001.

Sistemas Partidários em novas democracias: o caso do Brasil. Porto Alegre: "Os objetivos dos partidos sob regimes autoritários eleitorais ou

democracias frágeis: jogo em duas frentes". Revista Civitas, Porto Alegre, vol.2, n², p.249. 272, 2002.

MAIR, P. e KATZ, R How Parties Organize. Cambridge: Cambridge University Press, 1990.

MAIR, P. e BIEZEN, I. V. "Party Membership in Twenty European Democracies, 1980-2000". Party Politics, vol.7, $\mathrm{n}^{\circ} 1,2001$.

MELHEM, C. S. Política de Botinas Amarelas: O MDB.PMDB paulista de 1965 a 1988. São Paulo: Hucitec, 1998.

MENEGUELLO, R. Partidos e tendências de comportamento: o cenário político em 1994. In: DAGNINO, E. (Org.). Anos 90: política e sociedade no Brasil. São Paulo: Editora Brasiliense, 1994. 
BRAGA, M. S. S. Organizações partidárias e seleção de candidatos...

PANEBIANCO, A. Modelos de Partidos. Madri: Fundo de Cultura Econômica, 2005[1992].

PENNINGS, P. e HAZAN, R. Y. "Democratizing Candidate Method Selection: Causes and Consequences". Party Politics, vol.7, n³, 2001.

RAHAT, G. e HAZAN, R. Y. "Candidate Selection Methods An analytical framework". Political Studies, vol.7, n³, p. 297-322, 2001.

RANNEY, A. "Candidate Selection". In: BUTLER, D.; PENNIMAN, H. and RANNEY. A. (eds). Democracy at the Pol/s: a comparative study of competitive national elections. Washington DC: American Enterprise Institute of Public Research, 1981.

SAMUELS, D. "Determinantes do Voto Partidário em Sistemas Eleitorais Centrados no Candidato: Evidências sobre o Brasil”. Dados, vol.40, n³, Rio de Janeiro, 1997.

SANTOS, A. M. "Não se fazem mais oligarquias como antigamente. Recrutamento Parlamentar, experiência política e vínculos partidários entre deputados brasileiros (1946. 1998)". Tese de doutorado. UFRGS, 2000.

SARTORI, G. Parties and Party Systems. New York: Cambridge University Press, 1976.

SCHATTSCHNEIDER, E. E. Party Government. Nova York: Holt, Rinehart and Winston, 1941.

SCHLESINGER, J. Political Parties and the winning of office. AnnAnbor: The University Michigan Press, 1991.

TAVARES, J. A. G. Reforma Política e Retrocesso Democrático: agenda para Reformas pontuais no sistema eleitoral e partidário brasileiro. Porto Alegre: Mercado Aberto, 1998.

Maria do Socorro Souza Braga·socorros@ufsc.br

Recebido e aprovado para publicação em agosto de 2008. 